\title{
Evaluation of Versatile English Learning System using Webpages as Learning Materials
}

\author{
Yuki Oikawa, Kozo Mizutani, and Masayuki Arai
}

\begin{abstract}
In Japan, there is a strong demand for English language instruction not only from students, but also from working adults. However, the nation has few systems that have functions for improving English language skills (listening, speaking, reading, and writing) that are both inexpensive and simple to operate. In an effort to help resolve this problem, we developed a versatile English learning system that uses webpages as learning materials. The system has the following characteristics: it creates Japanese versions of webpages translated from English, it can determine a user's English skill level, it is capable of speaking and listening interactions, it does not require a subscription fee, and it is easy to operate. This paper reports on the results of an evaluation of our system.
\end{abstract}

Index Terms-English learning system, multi-functionality, webpage.

\section{INTRODUCTION}

In the face of increasing globalization, Japan's Ministry of Education, Culture, Sports, Science and Technology (MEXT) has mandated changes to the nation's high school English language curriculum. The goal of these changes is to develop students' English skills in the four areas of listening, speaking, reading, and writing by the time of their high school graduation. These skills are expected to be useful throughout their entire lives [1].

Additionally, today's working adults are also strongly motivated to improve their English skills because the number of overseas subsidiaries of Japanese companies has increased about four-fold in the past three decades, from 4,000 in 1979 to 17,000 in 2007 , and more than $70 \%$ of all Japanese companies now consider their employees' English skill levels to be more important than they did five years ago [2].

Thus, it is clear that the demand for English instruction is rising for working adults as well as for students. However, the nation has few systems in place for improving English skills (listening, speaking, reading, and writing) that are both inexpensive and simple to use. In an effort to help resolve this problem, we have developed a versatile English learning system that uses webpages as learning materials [3]. This

Manuscript received March 12, 2016; revised May 12, 2016. This study was supported in part by the Japan Society for the Promotion of Science, Grant Number: KAKENHI 15K01035.

Yuki Oikawa was with the Department of Human Information Systems, Faculty of Science and Engineering, Teikyo University, Tochigi, Japan.

Kozo Mizutani and Masayuki Arai are with the Department of Information and Electronic Engineering, Facultly of Science and Engineering, Teikyo University, Tochigi, Japan (e-mail: mizutani@ics.teikyo-u.ac.jp, arai@ics.teikyo-u.ac.jp). paper reports on the results of an evaluation of our system.

\section{SYSTEM OUTLINE}

Fig. 1 describes how to execute our system. First, users access a webpage of their choice, and then they click the "English Learning" button. This allows them to obtain the learning materials shown in the right side of the figure.

Fig. 2(a)-2(c) show the three panels of the client view of our system. Fig. 2(a) and 2(b) show an example of an English language webpage selected by a user and the same webpage translated into Japanese, respectively. Users can select unlearned or previously learned words, as shown in Fig. 2(c). Furthermore, as is also shown in Fig. 2(c), users can study speaking and listening and select their Test of English for International Communication (TOEIC) [4] level.

\section{SySTEM CONFIGURATION AND PROCEDURES}

Fig. 3 lays out the configuration and procedures of the system. First, a client computer (Fig. 3(a) ) accesses an English language Web server (Fig. 3(b) ) on the Internet and obtains English language learning materials based on the webpage received from our developed server (Fig. 3(c) ). One of the materials is a Japanese translation of the English language webpage generated by an English-Japanese translation server (Fig. 3(d) ).

The system process flow is as follows:

1) A client (Fig. 3(a)) accesses an English language Web server (Fig. 3(b)).

2) The Web server sends an English language webpage to the client.

3) The client connects to our server (Fig. 3(c) ) and transmits the uniform resource locater (URL) of the English language webpage.

4) Our server accesses the Web server using the URL.

5) Our server obtains the same English language webpage received by the client.

6) Our server divides the English language webpage into words and sends the words, their definitions, and their TOEIC levels to the client.

7) The client then connects to an English-Japanese translation server (Fig. 3(d)) and sends it the URL of the English language webpage.

8) The client receives the Japanese translation of the English language webpage from the translation server.

We used the hypertext markup language (HTML), cascading style sheets (CSS), and the JavaScript, Java Servlet, JQuery, and Web Speech application programming interfaces (APIs) to construct the system. Implementation methods for the system have been described in our previous paper [3]. 

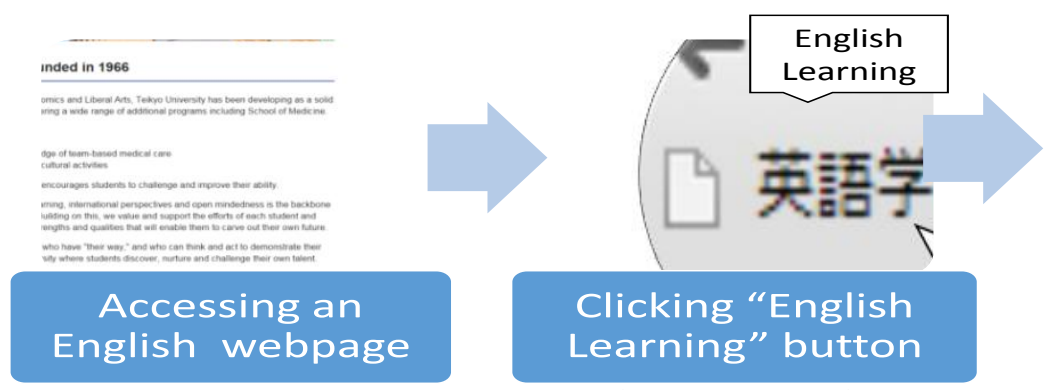

Clicking "English

Learning" button

Fig. 1. System execution.

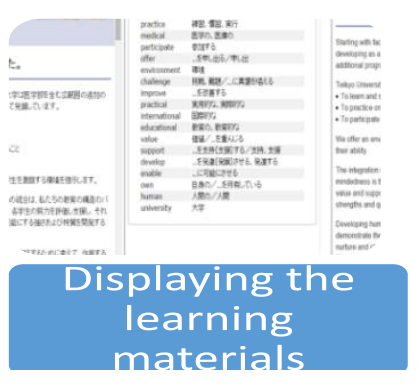

(c)

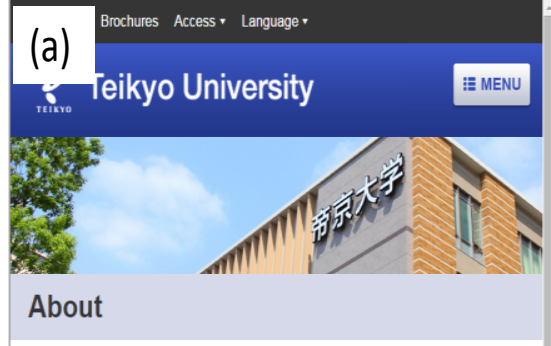

University was founded in 1966

Starting with faculties of Economics and Liberal Arts, Teikyo University has been developing as a solid comprehensive university, offering a

wide range of additional programs including School of Medicine.

Teikyo University is a place

- To learn and study

- To practice on the leading edge of team-based medical care

- To participate in sports and cultural activities

We offer an environment that encourages students to challenge and improve their ability.

The integration of practical learning, international perspectives and open mindedness is the backbone of our educational structure. Building on this, we value and support the efforts of each student and strive to help them develop strengths and qualities that will enable them to carve out their own future.

Developing human resources who have "their way," and who can think and act to demonstrate their own individualities. The university where students discover, nurture and challenge their own talent. We are Teikyo University. (b)

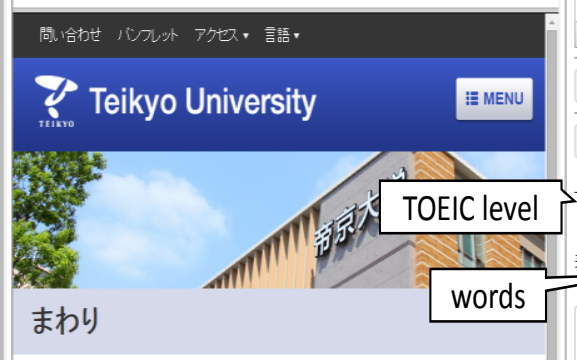

大学は1966年に設立されました

释济学上教養学科の能力て始まり，帝京大学か堅固な包括的大大学山一

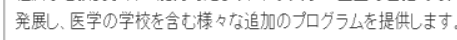

帝京大学は場所厄す

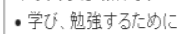

・チームベースの医療の最先端を練習するた奻に

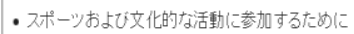

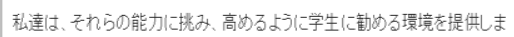
す。

実用的な学習、国際的なパースペクティプ、おひひ開いている心たての統合

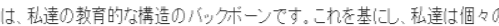

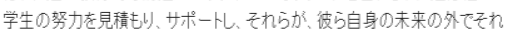

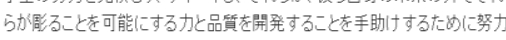
します。

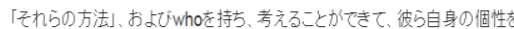

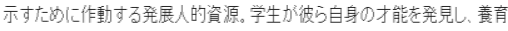
L, 挑尤大学。

Fig. 2. System overview.

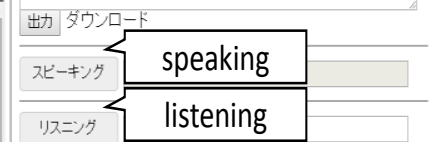

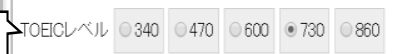

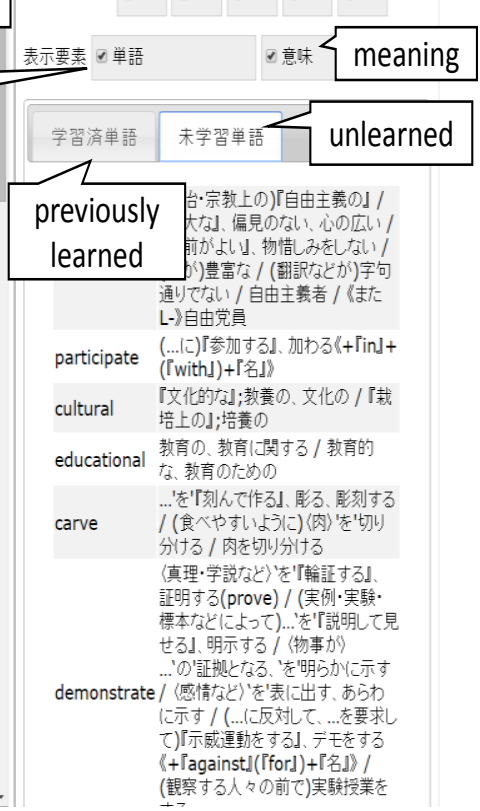

(b) English Web server

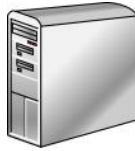

(c) Our developed server

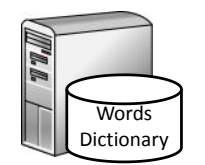

(3) $\downarrow$ (6)

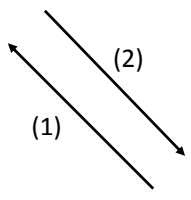

(a) Client

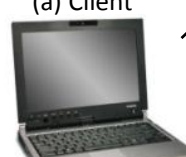

Web speech API

Fig. 3. System configuration and procedures.

\section{System Evaluation Method}

Seven students (three juniors and four seniors) and three faculty members of the School of Science and Engineering, Teikyo University were asked to assist in our evaluation. After using the system, a questionnaire was distributed so they could provide their assessments of the system.

The following questions were provided to help them evaluate the system:

1) Which functions did you use most frequently?

2) Rate the learning effectiveness of each function below:

- Displaying the definitions, example sentences, and related information for each word in a webpage

- Translating English webpage into Japanese

- Recognizing user's spoken English

- Listening to English pronunciation

3) Do you think the system is useful for learning English?

4) Do you hope to use the system again?

5) If you have some difficulties using the system, what were they?

6) What other functions would you like to see in the system?

7) Other opinions.

\section{EVALUATION RESULTS AND DISCUSSION}

\section{A. Question 1}

The results of Question 1 are shown in Fig. 4, where it can be seen that the most frequently used function was "to display meaning, example sentences, and related information for 
each word in a webpage" and the least frequently used function was "Recognizing the user's spoken English".

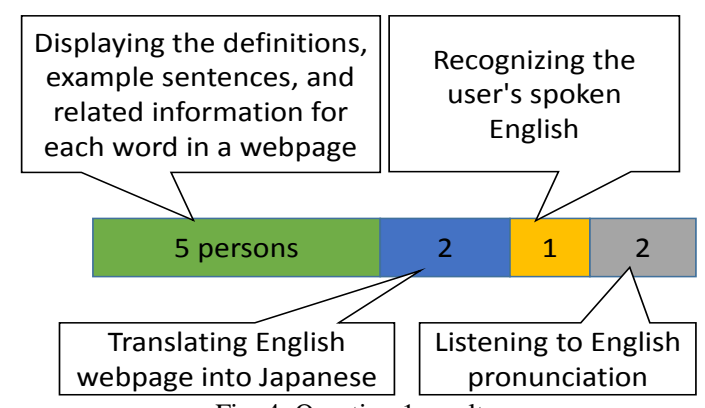

Fig. 4. Question 1 results.

\section{B. Question 2}

The results of Question 2 are shown in Fig. 5. Most users answered that the function of displaying the definitions and audio pronunciation of each word were effective or very effective. On the other hand, just one user said that the functions for translating English webpages into Japanese and recognizing in the user's spoken English were very effective.

(a) Displaying the definitions, example sentences, and related information for each word in a webpage

(b) Translating English webpage into Japanese

(c) Recognizing user's spoken English

(d) Listening to English pronunciation

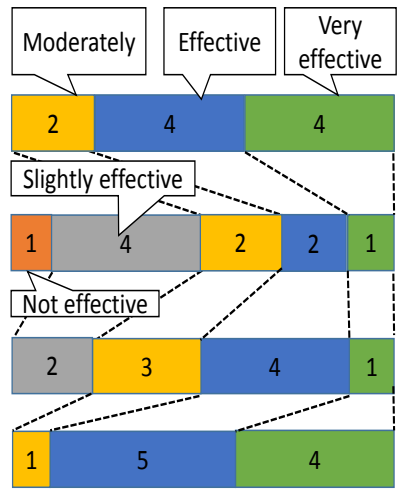

Fig. 5. Question 2 results.

\section{Questions 3 and 4}

The results of Questions 3 and 4 are shown in Fig. 6. Approximately $70 \%$ of the participants said the system was efficient for learning English and that they hoped to use it again.

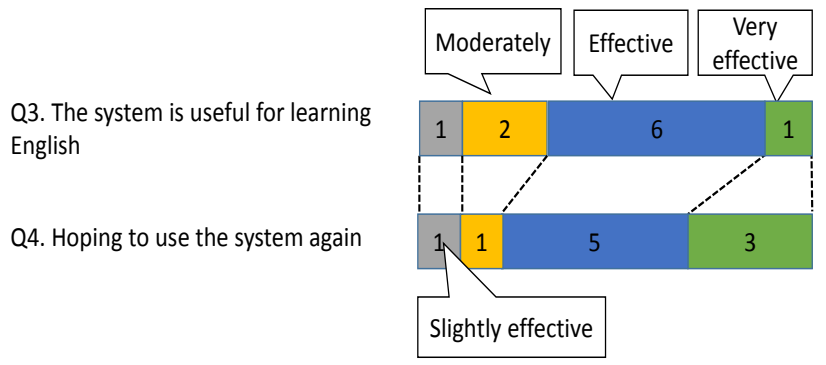

Fig. 6. Question 3 and 4 results.

\section{Question 5}

The Question 5 results, which are shown in Table I, indicate that in order to be effective, the system must do more than simply provide the pronunciations of each word. Sentence level pronunciation is definitely required, and the system's user interface must be improved.

\section{E. Question 6}

The Question 6 results are shown in Table II. Here, it can be seen that the participating users requested a number of additional functions for the system. However, since we think that an excessive number of functions would degrade the usability of the system, we will carefully consider priorities when implementing new functions.

TABLE I: QUESTION 5 RESULTS

It's difficult to recognize the position and difficulty level of the
words we want to study.
I cannot understand my skill level.
The system cannot provide pronunciation for each sentence.
Scrolling is different for each page, so it's difficult to use the system.

TABLE II: QUESTION 6 RESULTS

If a user selects an English word or sentence, the system should
point out corresponding Japanese versions.
A user management function, such as a user portfolio, would be
useful
A function that would help improve accents would be useful.
The system should display a ratio between unlearned and previously
learned words.
Translating Japanese sentences and paragraphs into English should
be supported.
A feature for listening to the pronunciation of words that are not on
the webpage would be useful.
Listening pronunciation for each sentence should be supported.
The system should provide word tests.
The system should be capable of displaying the definitions of all
words on a webpage.
The system should support the use of other document formats, such
as PDF.
A writing function should be supported.

\section{F. Question 7}

The Question 7 results are shown in Table III. Many users said that the system was very effective and useful because it was capable of implementing multiple functions.

TABLE III: RESULTS OF QUESTION 7

It's very convenient, because we can obtain large amounts of information in one system without using a dictionary and/or other tools.

\section{RELATED SYSTEMS AND RESEARCH}

In this section, we review some of the more popular English learning systems designed for Japanese users that are similar to our proposed system. For example, the P-Study System [5] employs four selectable modes and a typing mode for studying English words and idiomatic phrases. It also includes questions for junior high school students, the 2nd Grade of the Society for Testing English Proficiency (STEP) Test in Practical English Proficiency, and TOEIC. Additionally, users can learn English words and sentences via listening exercises and can confirm pronunciation for English words using the voice replay function.

Another system, Reader's Digest English20 [6], permits the use of movies and dramas and learners study English by listening to the characters talks. Additionally, AmiVoice ${ }^{\circledR}$ CALL -pronunciation- [7] and Hatsuon Kentei ${ }^{\circledR}$ [8] can be used for improving English speaking skills. These systems can record learners' pronunciation, analyze voices, compare them to the correct pronunciation, indicate incorrect articulation, and suggest improvements. For tablet and smartphone users, MyET [9] is available. This system allows users to recognize their weaknesses by listening to their own voices. Table III shows comparisons between the various 
English learning systems for Japanese learners, including our proposed system. As can be seen in the table, the unique characteristics of your system include its use of webpages and the fact that no installation is required.

\begin{tabular}{|c|c|c|c|c|c|c|}
\hline & $\begin{array}{l}\text { P-Study } \\
\text { System }\end{array}$ & $\begin{array}{l}\text { Reader's Digest } \\
\text { English20 }\end{array}$ & $\begin{array}{l}\text { AmiVoice }{ }^{\circledR} \text { CALL - } \\
\text { pronunciation- }\end{array}$ & $\begin{array}{l}\text { Hatsuon } \\
\text { Kentei }{ }^{\circledR}\end{array}$ & MyET & Our system \\
\hline Word Level Learning & $\checkmark$ & & & & & $\checkmark$ \\
\hline Sentence Level Learning & $\checkmark$ & & & & & $\checkmark$ \\
\hline Listening & $\checkmark$ & $\checkmark$ & & & & $\checkmark$ \\
\hline Speaking & & $\checkmark$ & $\checkmark$ & $\checkmark$ & $\checkmark$ & $\checkmark$ \\
\hline Writing & $\checkmark$ & $\checkmark$ & & & & \\
\hline $\begin{array}{l}\text { Using teaching materials in } \\
\text { accordance with the user's level }\end{array}$ & $\checkmark$ & & & & & $\checkmark$ \\
\hline Using favorite web pages & & & & & & $\checkmark$ \\
\hline Without installation & & & & & & $\checkmark$ \\
\hline Simple operation & $\checkmark$ & $\checkmark$ & $\checkmark$ & $\checkmark$ & $\checkmark$ & $\checkmark$ \\
\hline
\end{tabular}

Sano et al. studied using webpages for learning English [10]. The goal of their research was to develop a learning system that could provide free English materials adapted to the needs of each learner. Therefore, their paper proposed a way to extract learning materials from a corpus consisting of webpages and evaluated the difficulty of the material.

\section{CONCLUSION}

In this paper, we described an English learning system that uses webpages as learning materials. In the sections above, we discussed the outline and characteristics of the proposed system. As part of our future studies, we intend to implement a function that will permit the system to recommend appropriate learning materials based on each user's skill levels, and will evaluate this system via practical use in actual classes. The evaluation results achieved to date show that the system is effective for helping students improve their listening skills and learn English words.

\section{ACKNOWLEDGMENTS}

The authors would like to thank the members of the Arai Laboratory, Department of Human Information Systems, School of Science and Engineering, Teikyo University, and the Graduate School of Science and Engineering, Teikyo University for their useful advice and help in the system evaluation.

\section{REFERENCES}

[1] The Ministry of Education, Culture, Sports, Science and Technology Japan. (May 5, 2016). [Online]. Available: http://www.mext.go.jp/b_menu/shingi/chousa/shotou/102/houkoku/att ach/1352463

[2] I. Koike, S. Takada, J. Matsui, and H. Terauchi, English Skills: What Do Companies really Need, Asahi Press, 2010.

[3] Y. Oikawa, K. Mizutani, and M. Arai, "Versatile English learning system using webpages as learning materials," in Proc. 22nd International Conference (ICONIP 2015), Proceedings, Part II, pp. 380-389, Nov. 2015

[4] TOEIC. (May 5, 2016). [Online]. Available: http://www.toeic.or.jp
[5] P-Study System. (May 5, 2016). [Online]. Available: http://www.takke.jp/

[6] Reader's Digest English 20. (May 5, 2016) [Online]. Available: http://www.sourcenext.com/product/pc/edu/pc_edu_000654/

[7] AmiVoice® CALL-pronunciation. (May 5, 2016). [Online]. Available: http://www.advanced-media.co.jp/products/amivoicecallpronunciatio n.html

[8] Hatsuon Kentei®. (May 5, 2016). [Online]. Available: http://www.prontest.co.jp/wp/new-bar/

[9] MyET. (May 5, 2016). [Online]. Available: http://www.alc.co.jp/speaking/myet/

[10] H. Sano and M. Ino, "Measurement of difficulty on English grammar and automatic analysis," IPSJ Transactions on CE, no. 117, pp. 1-12, 2000.

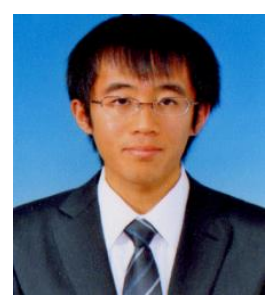

Yuki Oikawa graduated from the Department of Human Information System, Faculty of Science and Engineering, Teikyo University, Japan in 2015. He primarily engaged in information processing. At present, he works in M.SOFT CO. LTD.

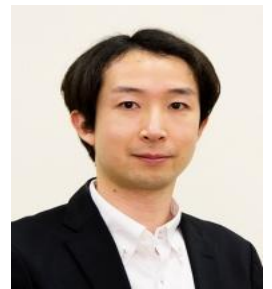

Kozo Mizutani received his B.E. degree from Teikyo University in 2000. He worked Fujisoft ABC Inc. (now Fujisoft Inc.) in 2000 and BB Technology Corp. (now SoftBank BB Corp.) in 2002. He received his M.E. and D.E. degrees from the Graduate School of Science and Engineering at Teikyo University in 2005 and 2008, respectively. He worked as an assistant professor at Medical Information and Systems Research Center, Teikyo University from 2008. Since 2014, he has been working as a lecturer at the Department of Information and Electronic Engineering, Faculty of Science and Engineering, Teikyo University. He is a member of IEICE, IPSJ, JSiSE and JAMI.

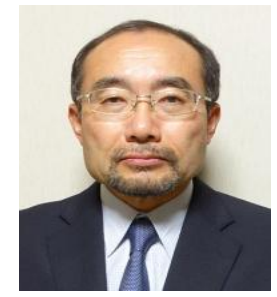

Masayuki Arai is a professor in the Graduate School of Sciences and Engineering at Teikyo University. He received his B.E. degree from Tokyo University of Science in 1981 and Dr. Eng. degree from Utsunomiya University in 1995 . His research interests include pattern recognition, natural language processing and information visualization. He is a member of the Information Processing Society of Japan and IEEE. 